\title{
A PROBLEM OF TOXIC WASTE OF ST PETERSBURG
}

\author{
Irina Luchkina ${ }^{I}$ \\ Sergey Kirsanov ${ }^{2}$ \\ 'Municipality of Kolpino, Russia \\ ${ }^{2}$ St. Petersburg State University of Engineering and Economics, Russia
}

\section{INTRODUCTION}

21 century is remarkable for a prompt growth of manufacture which provides an environment with huge quantity of the waste leading its degradation and creating the real threat to health and people's life. Considering the high importance of a problem of the reference with waste, it is important to expand researches in this direction. This problem can be solved by combined efforts of scientists and experts of various fields of knowledge.

The problem of the use of waste begins with their formation at the plants, factories etc. In Saint-Petersburg and Leningrad region operate about 20000 enterprises on which are formed about 40000 tons of liquid and about 5 million square meters of firm waste a year. Use, neutralization and transportation of waste is carried out by enterprises if they have for this purpose technological and technical opportunities, and by organizations, engaged to work in given kinds of activity. Waste which cannot be used is buried what means it is kept isolated in special storehouses for a purpose of prevention the environment.

By the decision of the government in 1967 in 30 kilometers from Saint-Petersburg and 4.5 kilometers from the town Kolpino (where live about 140000 citizens nowadays) has been created a Range for reception and distribution of all toxic waste of the region. This place was chosen because beds of blue Cambrian loam are close to the earth level. Their thickness is about 80 meters. The process of treatment of the waste is quite easy: the upper level of loamy soil was thrown away and deep foundation pits were dug in a loam to put in all poison waste. Nobody paid attention to the fact that in 3 kilometer sanitary-protective zone several villages are located and not far from it there is a watershed of the rivers Neva, Izhora and Tosna.

About 40 years have passed. The Range which had been creating for about 15-20 years became one of the most dreadful potential dangers for the whole Baltic region. About several millions of cubes of different kinds of poisons and toxicants are kept within 80 hectares of the Range. Foundation pits' contents affect the environment and is dangerous a lot for the people's health. Cambrian loam is heterogeneous and has a lot of clefts and send layers. It is necessary to build cutting wall which would not allow to creep away the toxic waste. It is necessary to carry out researches of seismicity of this area to understand the degree of risk. It is impossible to predict what consequences will be in case of an extreme situation. 


\section{TECHNICAL CHARACTERISTICS OF A RANGE}

The range is shafted to prevent the environmental of getting the polluted waters the territory of. The shaft is made of the stamped cambrian loam. On an external contour for interception superficial and subsoil waters and their tap the ring channel is lead to the river Greater Izhorka. The range is equipped by a system of internal drainage a cuvette. The system is connected to a pond-store, where the polluted storm waters move for neutralization on installations of themal neutralization.

All the toxic waste accepted in the Range is divided into groups:

- liquid waste of inorganic structure (waste of galvanic manufactures and liquid glass),

- liquid waste of organic structure (emulsions, pitches and mineral oil),

- firm (paste-like waste of organic and inorganic structure: sludges of the galvanic manufactures, the ground polluted by mineral oil,

- 1st class of toxicity is especially harmful (waste containing mercury, cyanogen, arsenic, chrome).

Waste is accepted in foundation pits which sizes are: width is $30-120 \mathrm{~m}$, length is $40-200 \mathrm{~m}$ and depth is from 6 up to $24 \mathrm{~m}$. Liquid waste of organic and inorganic structure is neutralized by decreasing of their class of toxicity. Firm and especially toxic waste is buried.

The ecological situation which has been developed in the Range's area is unique. The problem of moving of harmful admixture in contiguous environments and elements of a landscape is an important step for an estimation of consequences of their influence on ecosystems. Harmful admixtures move into environment from sources by two ways: air and water.

There is a negative Range's influence on all components of the environment. We shall view the influence on each component.

\section{INFLUENCE ON WOOD VEGETATION AND BIOLOGICAL ACTIVITY OF LANDS}

The northeast part of the Range sides with a site of strongly damaged plantings. Its configuration and coincidence with a projection of smoky-gas smoke of the Range's furnaces unambiguously specify that furnaces are the reason of destruction of wood vegetation. The basic type of air pollution is acid, caused by discharges of decay products of mineral oil and organic chemistry, first of all $\mathrm{SO}_{2}$ and its derivatives and also oxides of nitrogen. The real influence of the Range on microorganisms is fixed on a whole perimeter, especially it is noticed on northwest periphery, in area of the by-pass channel where the stressful condition of microorganisms is revealed.

\section{INFLUENCE ON AN ATMOSPHERE}

Sources of receipt of harmful substances into atmosphere from territory of Range are: foundation pits, furnaces for burning organic waste, a boiler-house and motor transport. Above the Range are found the following connections: acetone, hexane, heptane, nonane, threechlorinemetan, benzol, terpenes, etc. The Range's influence on a condition of the 
atmosphere is expressed in a some kind of enrichment of atmospheric falling by soluble (steam and gas) forms of some elements.

\section{INFLUENCE ON HYDROSYSTEM}

Despite of a huge pollution by heavy metals of all environments of the Range, their distribution across the limits of an industrial platform is selective. The waterway of migration prevails. The sites of the ground framing the Range from the north and the west have been massed polluted. As a result peatbogs are low biologically active and the wood is becoming degraded.

\section{A PROBLEM OF DIOXIN POLLUTION}

The basic danger of dioxins consists not only in their sharp toxicity, and basically in cumulative action and the remote consequences of a chronic poisoning with the smallest dozes. Experts, solving a problem of division into districts of the area in degrees of pollution toxicant dioxin's row, have studied distribution of the sum of polychlorinebiphenyls (PCB) in the ground. The estimation of the received results shows rather non-uniform character of pollution of ground and plants. The basic contribution to pollution of ground PCB belongs to processes of exhalation of the chamber of evaporation of liquid organic waste located in the ground.

\section{GEOLOGICAL FEATURES OF THE RANGE}

The reasons of negative influence of the Range on an environment are imperfect technology of storage of liquid waste, processing and their burial places. It is established, that from the Range there are underground drains, which bear toxic substances in natural hydro system surrounding it.

Summing up, it is possible to make a conclusion, that engineering-geological conditions on the Range is rather complex, and completeness of available data to it are not adequate. For prevention of the further pollution it is necessary to process collected waste, and to utilize at once again acting, not subjecting to a burial. For realization of this problem it is necessary to accelerate construction of a factory on processing toxic waste.

\section{MODERN TECHNOLOGIES OF THE REFERENCE WITH TOXIC WASTE}

The analysis of experience of foreign countries shows, that an output from the created situation with neutralization of waste is the organization of system of complex use and neutralization of waste. The analytical work should precede the development of the given system including: definition of tendencies in change of volumes of formation of waste and their qualitative structure in region, a choice of economically comprehensible and technically possible ways of neutralization and use of waste, creation of databases on technological and consumer properties of waste.

Following methods of processing of similar waste are known:

A method of high-temperature oxidation at a heat at presence of oxygen of air (gascore oxidation at $\mathrm{t}>1100^{\circ}$ and liquid-phase oxidation in autoclaves at $\mathrm{t}>300^{\circ} \mathrm{P}>100$ atm); 
- Chemical methods (coagulation, processing by strong oxidizers - chlorine, ozone);

- Biochemical oxidation;

- Membrane methods;

- Thermal methods.

The method of high-temperature oxidation is certainly reliable, but demands more capital and operational costs, than other methods. Chemical methods of processing do not allow to achieve the necessary degree corresponding requirements of the nature protection legislation. The method of biochemical clearing, in this case, cannot be applied, since does not reduce the maintenance of inorganic components, and concentration of organic substances in an initial solution on two orders above, than is required for reliable work of station of biochemical clearing.

The method of membrane technologies is high-sensitivity to change of structure of an initial solution that makes work of installation unreliable since the structure of waste of the Range considerably varies from depth of selection, a season.

The thermal method is widely applied to processing similar complex waste. The essence of this method consists that all known organic connections can be oxidized by oxygen of air at temperatures 1000-1200 ' $\mathrm{C}$ up to simple thermodynamic steady connections. The presence of such elements as chlorine, fluorine, sulfur, and phosphorus at organic substances conducts to secondary pollution. Therefore at burning these connections before dump in an atmosphere it is necessary to subject smoke gases to additional clearing.

Ecological and economic efficiency of process of thermal neutralization is defined by an overall performance of the basic device - furnaces of burning.

The problem of neutralization of not utilized inorganic waste which cannot be transformed into useful resources, is solved by their physical and chemical processing. The most widespread way is physical and chemical processing by a reagent method, with the subsequent neutralization on the filtering equipment, packing and a burial place on a special dump in tight bunkers.

\section{PROSPECTS OF FURTHER USE OF THE RANGE}

In connection with that the areas for a burial place of waste on the Range are practically developed, there is necessary an all-round acceleration of construction of the enterprise on processing and a burial place of toxic industrial wastes. Commissioning of such enterprise on full capacity should solve nature protection problems of all Northwest region Russian Federation. The main problem is practically absence of financing for its construction. The international help is necessary. First of all it is necessary to create legal base, which would protect interests of investors. The factory can become financial attractive and be repaid. Other important problem is putting in order with licensing the enterprises, which are engaged in transportation of toxic waste in region. In region cases of not authorized accommodation of dangerous waste not in the territory of Range are widespread. Inhabitants of St.-Petersburg should be evacuated, because the unique source of potable water will be polluted.

40 years ago nobody could believe that cannot find resources in the huge rich country for construction in Northwest of a factory on processing dangerous waste. But actually, today we 
have ecologically dangerous object, range "the Red Pine Forest" which threatens not only to St.-Petersburg, but also the countries of the Baltic region. In opinion of experts, in case of break of a collapse of foundation ditches, waste in 40 minutes will get to Neva and further to Baltic Sea. If the factory will not be constructed, accident, which can be compared on consequences with Chernobyl, is inevitable. Inhabitants of St.-Petersburg should be evacuated, because the unique source of drinking water will be polluted.

There are no doubts, that in region in the shortest terms it is necessary to complete a factory on processing toxic waste and in this situation Russia will be grateful for any help of our countries-neighbors. 